\title{
Postprandial Glucagon Reductions Correlate to Reductions in Postprandial Glucose and Glycated Hemoglobin with Lixisenatide Treatment in Type 2 Diabetes Mellitus: A Post Hoc Analysis
}

Bo Ahrén · Gagik Galstyan · Jean-Francois Gautier • Francesco Giorgino •

Fernando Gomez-Peralta • Michael Krebs • Elena Nikonova •

William Stager · Hernando Vargas-Uricoechea

Received: April 7, 2016 / Published online: June 18, 2016

(C) The Author(s) 2016. This article is published with open access at Springerlink.com

\section{ABSTRACT}

Introduction: The extent to which postprandial glucagon reductions contribute to lowering of postprandial glucose in patients with type 2 diabetes mellitus (T2DM) is currently unknown. The aim of this analysis was to determine whether a reduction in postprandial glucagon following treatment with the glucagon-like peptide-1 receptor agonist lixisenatide correlates with a reduction

Enhanced content To view enhanced content for this article go to www.medengine.com/Redeem/ E9D4F060614CD9B3.

B. Ahrén $(\bowtie)$

Lund University, Lund, Sweden

e-mail: bo.ahren@med.lu.se

G. Galstyan

National Centre of Endocrinology, Moscow, Russian Federation

J.-F. Gautier

Lariboisière Hospital, Paris, France

F. Giorgino

University of Bari Aldo Moro, Bari, Italy

F. Gomez-Peralta

Hospital General de Segovia, Segovia, Spain in postprandial glucose and glycated hemoglobin $\left(\mathrm{HbA}_{1 \mathrm{c}}\right)$ in patients with T2DM.

Methods: A post hoc analysis was performed on pooled data from the modified intent-to-treat populations of two lixisenatide Phase 3 trials: GetGoal-M (lixisenatide versus placebo as add-on to metformin) and GetGoal-S (lixisenatide versus placebo as add-on to sulfonylurea $[\mathrm{SU}] \pm$ metformin). Glucagon levels were assessed $2 \mathrm{~h}$ after a standardized meal test performed at baseline and Week 24 and were examined for correlation with changes in 2-h postprandial glucose and $\mathrm{HbA}_{1 \mathrm{c}}$.

Results: Lixisenatide reduced 2-h postprandial glucagon at Week 24 compared with placebo $(P<0.00001)$. The mean change in postprandial

M. Krebs

Medical University of Vienna, Vienna, Austria

E. Nikonova

Artech Information Systems, LLC, Morristown, NJ, USA

W. Stager

Sanofi, Bridgewater, NJ, USA

H. Vargas-Uricoechea

Hospital Universitario San José, Popayán, Colombia 
glucagon significantly correlated with reductions in postprandial glucose $(P<0.00001)$ and $\operatorname{HbA}_{1 \mathrm{c}}(P<0.00001)$.

Conclusion: A reduction in postprandial glucagon following lixisenatide administration correlated with a decrease in postprandial glucose and $\mathrm{HbA}_{1 \mathrm{c}}$ in patients with T2DM insufficiently controlled on metformin and/or SU. This suggests that lowering of postprandial glucagon contributes to the overall glycemic improvement observed with lixisenatide.

Funding: Sanofi.

Clinical Trial Numbers: NCT00712673 (GetGoal-M) and NCT00713830 (GetGoal-S).

Keywords: Glucagon; Glucagon-like peptide-1 receptor agonist; Glycemic control; Lixisenatide; Prandial; Type 2 diabetes mellitus

\section{INTRODUCTION}

In type 2 diabetes mellitus (T2DM), defective insulin secretion and augmented glucagon secretion contribute to glucose dysregulation $[1,2]$. These defects are targeted by the incretin glucagon-like peptide-1 (GLP-1) [3] and, therefore, GLP-1 receptor agonists (GLP-1 RAs) lower glycated hemoglobin $\left(\mathrm{HbA}_{1 \mathrm{c}}\right)$ [4]. In particular, a reduction in postprandial glucagon secretion by GLP-1 RAs may be of importance for reduced glucose excursion after a meal (postprandial glucose), which is a necessary component of improving glycemic control $[5,6]$. However, to what extent postprandial glucagon reductions contribute to the lowering of postprandial glucose excursions in individuals with T2DM is unknown.

Lixisenatide (Lyxumia ${ }^{\circledR}$, Sanofi, Paris, France), a novel GLP-1 RA [7], has been shown to inhibit glucagon release [8] and to markedly reduce postprandial glucagon in individuals with T2DM [9]. This suggests that a reduction in glucagon may be a clinically important mechanism underlying the improved glycemic control observed following lixisenatide administration.

To examine whether reduced postprandial glucagon is of relevance for improved postprandial glucose, we examined whether the reduction in postprandial glucagon observed following treatment with lixisenatide correlates to improved glycemic outcome in two placebo-controlled Phase 3 trials (GetGoal-M [NCT00712673] and GetGoal-S [NCT00713830]). GetGoal-M assessed the efficacy of lixisenatide on glycemic control versus placebo as add-on to metformin, whereas GetGoal-S assessed lixisenatide versus placebo as add-on to sulfonylurea (SU) \pm metformin $[10,11]$.

\section{METHODS}

\section{Overall Study Design}

This analysis follows a previously published analysis that investigated the effects of lixisenatide on postprandial glucose, glucagon, and insulin after a meal test [9]. Briefly, a post hoc analysis was performed of pooled data from the modified intent-to-treat populations of two of the lixisenatide Phase 3 trials-GetGoal-M and GetGoal-S.

\section{Inclusion Criteria}

As reported previously [10, 11], GetGoal-M and GetGoal-S included patients who had T2DM for $\geq 1$ year and $\mathrm{HbA}_{1 \mathrm{c}}$ levels of $7-10 \%$. Patients in GetGoal-M were insufficiently controlled with metformin at a stable dose of $\geq 1.5 \mathrm{~g}$ per day for $\geq 3$ months. Patients in GetGoal-S had been receiving a stable dose of an SU alone or in combination with metformin $(\geq 1.5 \mathrm{~g}$ per day $[\geq 0.75 \mathrm{~g}$ per day in Japan and $\geq 1.0 \mathrm{~g}$ per day in South Korea]) for $\geq 3$ months. GetGoal-M and 
GetGoal-S were included in this post hoc analysis because these are the only studies from the GetGoal clinical trial program to assess plasma glucagon levels.

\section{Interventions}

Lixisenatide $20 \mu \mathrm{g}$ once daily or placebo was administered for 24 weeks as an add-on to metformin (GetGoal-M) or $\mathrm{SU} \pm$ metformin (GetGoal-S). Each of these studies included a standardized meal test performed after an overnight fast. Only patients who administered lixisenatide before breakfast were included in the standardized meal test. Lixisenatide was administered exactly $30 \mathrm{~min}$ prior to the meal. The analysis population in the present study was the modified intent-to-treat population (all randomized and treated patients who had a baseline and post-baseline meal test assessment).

Glucagon levels were assessed during fasting and $2 \mathrm{~h}$ after a standardized meal test performed at baseline and at Week 24. Blood samples were drawn $30 \mathrm{~min}$ prior to and $2 \mathrm{~h}$ after a calorie-controlled breakfast $(400 \mathrm{~mL}$ of Ensure Plus $^{\circledR}$, Abbott Nutrition, Columbus, OH, USA). The concentration of plasma glucagon was assessed using the Millipore/LINCO Glucagon Radioimmunoassay kit (Millipore, Billerica, MA, USA), which utilizes ${ }^{125}$ I-labeled glucagon and glucagon antiserum to determine the level of glucagon in plasma using the double-antibody/ polyethylene glycol technique.

\section{Outcome Measures and Statistical Analysis}

For the purposes of this post hoc analysis, outcome measures at Week 24 were change from baseline in 2-h postprandial glucagon. Correlation between change from baseline in postprandial glucagon and 2-h postprandial glucose, and from baseline in postprandial glucagon and $\mathrm{HbA}_{1 \mathrm{c}}$ were also assessed at Week 24. Least squares mean differences between treatments in glucagon outcomes were obtained from an analysis of covariance using a linear model including treatment group, study randomization strata $\left(\mathrm{HbA}_{1 \mathrm{c}}[<8.0 \%, \geq 8.0 \%]\right.$ and metformin use [yes/no; GetGoal-S] or body mass index $\left[<30 \mathrm{~kg} / \mathrm{m}^{2}, \geq 30 \mathrm{~kg} / \mathrm{m}^{2}\right.$; GetGoal-M]) and country as fixed effects, and the corresponding baseline endpoint value as a covariate. Analyses include all patients with baseline and follow-up glucagon assessments and used the last observation carried forward values through Week 24 . To control type I errors, a multiplicity adjustment was made by considering only results with a $P$ value of $<0.01$ as significant. To determine the correlation between glucagon and glycemic outcomes, Pearson correlation statistics were calculated for each study and combined using normalized Fisher $z$-transformed values. Results of all analyses were combined across studies using fixed-effect meta-analysis with inverse variance weights (RevMan 5.2; The Nordic Cochrane Centre, The Cochrane Collaboration, Copenhagen, Denmark). Linear regression modeling was performed using SAS ${ }^{\circledR} 9.2$ (SAS Institute Inc., Cary, NC, USA).

\section{Compliance with Ethics Guidelines}

The analysis in this article is based on previously conducted studies and does not involve any new studies of human or animal subjects performed by any of the authors.

\section{RESULTS}

A total of 425 lixisenatide-treated patients and 176 placebo-treated patients had baseline and follow-up assessments for 2-h postprandial glucagon and were included in the analyses. 
Table 1 Overall mean baseline demographics and clinical parameters across treatment arms-safety populations

\begin{tabular}{lll}
\hline Characteristics & $\begin{array}{l}\text { Lixisenatide } \\
(\boldsymbol{n}=\mathbf{4 2 5})\end{array}$ & $\begin{array}{l}\text { Placebo } \\
(\boldsymbol{n}=\mathbf{1 7 6})\end{array}$ \\
\hline Age, years & $55.7(9.6)$ & $56.6(10.7)$ \\
Male, \% & 44.5 & 52.3 \\
Caucasian/Asian, \% & 94.8 & 96.6 \\
$\mathrm{BMI}, \mathrm{kg} / \mathrm{m}^{2}$ & $31.7(7.3)$ & $31.3(6.9)$ \\
$\mathrm{HbA}_{1 \mathrm{c}} \%$ & $8.2(0.9)$ & $8.2(0.8)$ \\
$\mathrm{FPG}, \mathrm{mmol} / \mathrm{L}$ & $9.5(2.1)$ & $9.1(2.2)$ \\
Diabetes duration, years & $8.1(6.1)$ & $8.8(6.5)$ \\
\hline
\end{tabular}

All values are mean (standard deviation) unless stated otherwise

$B M I$ body mass index, $F P G$ fasting plasma glucose, $H b A_{\text {Ic }}$ glycated hemoglobin

Combined baseline demographics and characteristics for GetGoal-M and GetGoal-S are summarized in Table 1.

\section{Glucagon Outcomes}

At Week 24, mean (standard error) 2-h postprandial glucagon levels were markedly reduced from baseline in the lixisenatide arm (from 99.0 [1.6] to 74.9 [1.4] ng/L; $P<0.00001$ ) and slightly reduced in the placebo arm (from 98.8 [2.7] to 93.2 [2.7] ng/L; $P=0.12$ ), resulting in significantly lower postprandial glucagon in the lixisenatide arm compared with the placebo arm at Week $24(P<0.00001)$. Mean (standard error) percentage change in 2-h glucagon from baseline at Week 24 was significantly greater in the lixisenatide treatment arm versus the placebo arm (-21.3 [1.9] versus -1.9 [2.4]; $P<0.00001)$.

\section{Correlation Between Postprandial Glucagon and Postprandial Glucose and $\mathrm{HbA}_{1 \mathrm{c}}$ Levels}

At Week 24, least squares mean placebo-adjusted percent changes in postprandial glucose and $\mathrm{HbA}_{1 \mathrm{c}}$ were $-33.1 \%$ and $-7.7 \%$, respectively.

Change from baseline at Week 24 in postprandial glucagon levels positively correlated with the reduction in postprandial glucose levels in patients treated with lixisenatide $\quad(r=0.34 ; \quad P<0.00001 ; \quad$ Fig. 1a $)$. There was also a weak borderline significant correlation in placebo-treated patients $(r=0.19$; $P=0.01$; Fig. 1a). Change from baseline in postprandial glucagon levels also positively correlated with the reduction in $\mathrm{HbA}_{1 \mathrm{c}}$ at Week 24 in the lixisenatide-treated patients $(r=0.26 ; \quad P<0.00001 ; \quad$ Fig. $1 b), \quad$ while no correlation was observed in the placebo-treated patients ( $r=0.00 ; P=0.97$; Fig. $1 b)$.

\section{DISCUSSION}

We showed previously that lixisenatide $20 \mu \mathrm{g}$ once daily is associated with a significant reduction from baseline to Week 24 in 2-h postprandial glucagon versus placebo in patients with T2DM insufficiently controlled on metformin and/or SU [9]. The novel finding in this current report is that the reduction in postprandial glucagon in lixisenatide-treated patients positively correlates with reduced postprandial glucose and $\mathrm{HbA}_{1 \mathrm{c}}$ and that this is seen in patients on metformin, as well as SU.

A reduction in postprandial glucagon by lixisenatide has also been reported by Lorenz et al. in patients with T2DM treated with $\leq 2$ oral glucose-lowering agents [12] and by Meier et al. in patients administering insulin glargine \pm metformin [13]. This shows that one of the mechanisms of lixisenatide in T2DM is to reduce postprandial glucagon. The data described herein suggest that this effect may contribute to the lowering of blood glucose concentrations, as demonstrated by the direct positive correlation of 2-h glucagon reductions 
a

Lixisenatide arm

Total $(99 \% \mathrm{Cl})$

$P=0 \% ; P<0.00001$

Placebo arm

Total $(99 \% \mathrm{Cl})$

$R=0 \% ; P=0.01$

b

Lixisenatide arm

Total $(99 \% \mathrm{Cl})$

$F^{R}=62 \% ; P<0.00001$

Placebo arm

Total $(99 \% \mathrm{Cl})$

$R=0 \% ; P=0.97$

\section{Correlation Fisher-z}

IV, Fixed, $99 \% \mathrm{Cl}$

$0.34(0.24,0.48)$

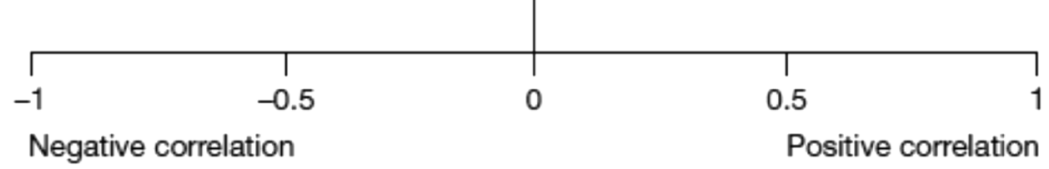

\section{Correlation Fisher-Z}

IV, Fixed, $99 \% \mathrm{CI}$

$0.19(-0.01,0.39)$

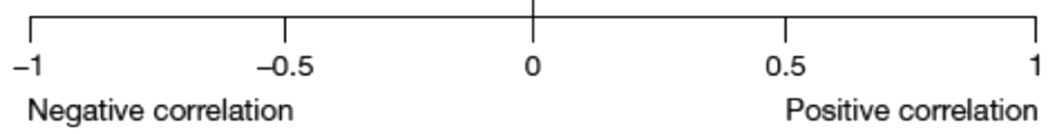

Negative correlation

\section{Correlation Fisher-z}

IV, Fixed, $99 \% \mathrm{Cl}$

$0.26(0.13,0.39)$

$\begin{array}{ll}-1 & \\ -1 & -0.5\end{array}$

Negative correlation

Positive correlation

\section{Correlation Fisher-z}

IV, Fixed, $99 \% \mathrm{CI}$

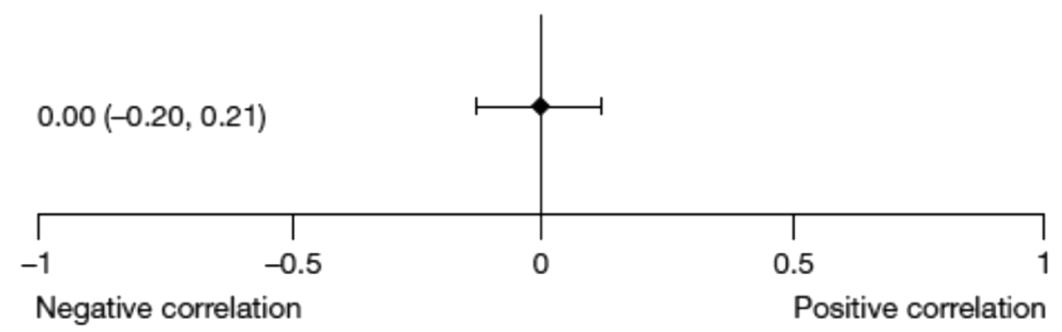

Negative correlation

Fig. 1 Correlation between change in postprandial glucagon and change in a postprandial glucose and $\mathbf{b} \mathrm{HbA}_{1 \mathrm{c}}$ in the lixisenatide treatment arm and the placebo arm at Week 24. CI Confidence interval

with decreases in postprandial glucose and $\mathrm{HbA}_{1 \mathrm{c}}$. Such an effect may be achieved by a reduction in hepatic glucose production by the lowering of glucagon, as it is known that there is a linear relationship between portal glucagon levels and hepatic glucose production [14]. 
Hence, a reduction in glucagon may play an important role in improved glycemic control following lixisenatide administration. However, since these studies were neither designed nor powered to demonstrate the causality between the two effects, this post hoc analysis focused on correlation only. There was a slight, although significant, reduction in postprandial glucose in the placebo group, which was positively correlated with change in glucagon. The correlation was marginally significant, possibly due to the relatively small sample size. However, there was no evidence of correlation between change in $\mathrm{HbA}_{1 \mathrm{c}}$ and change in glucagon in the placebo group. Interestingly, a recent study by Kramer et al. has reported that chronic liraglutide treatment is associated with a paradoxical enhancement in hyperglucagonemia, which emerged 12 weeks after treatment initiation and persists over a 48-week treatment period, together with sustained glycemic control. The authors suggest that the glucose-lowering effects of liraglutide may not be due to the postprandial reduction in glucagon that is observed with short-term treatment, speculating that long-term benefits may be due to $\alpha$-cell compensation [15].

The mechanism underlying the reduction in postprandial glucagon by lixisenatide was not established in this post hoc analysis of two Phase 3 studies. Two important mechanisms may, however, be involved. One mechanism is the direct inhibition of glucagon secretion from the islets, which is a well-known effect of GLP-1 $[3,4]$, and is also observed with lixisenatide [8]. Another mechanism is an indirect effect through delayed gastric emptying. A delay in gastric emptying is a well-known effect of lixisenatide [12,13] and results in diminished nutrient appearance in the circulation, thereby reducing the stimulation of islet function. Such a mechanism may also explain the reduction in 2-h postprandial insulin following lixisenatide administration [9], as demonstrated previously following exenatide twice-daily treatment [16].

The data described herein contribute to our understanding of how lixisenatide provides glycemic control in patients with T2DM; however, certain limitations should be acknowledged. First, the populations included in the two studies forming the basis of this post hoc analysis showed some differences in that patients in GetGoal-M had a higher body mass index than those in GetGoal-S, whereas GetGoal-S included a higher number of patients from Asia and patients with a longer duration of T2DM. Further investigations may address whether this heterogeneity is of importance for treatment with lixisenatide. Second, the current study does not provide any insight into the relative contribution of lixisenatide in the suppression of gastric emptying or the direct effect of lixisenatide on specific islet cells; this needs to be addressed in future mechanistic studies.

\section{CONCLUSION}

In conclusion, this post hoc analysis suggests that the reduction of postprandial glucagon by lixisenatide contributes to reduced postprandial glucose and $\mathrm{HbA}_{1 \mathrm{c}}$ in patients with T2DM insufficiently controlled on metformin and/or SU.

\section{ACKNOWLEDGMENTS}

Sponsorship and article processing charges for this study were funded by Sanofi. Editorial assistance was provided by Sarah Addison, $\mathrm{PhD}$, of Caudex (London, UK) and was funded by Sanofi. All named authors meet the International Committee of Medical Journal Editors (ICMJE) criteria for authorship for this 
manuscript, take responsibility for the integrity of the work as a whole, and have given final approval to the version to be published. All authors contributed to the writing of this manuscript and provided data analysis or interpretation. Bo Ahrén, Elena Nikonova, and William Stager contributed to the design of the study. Bo Ahrén contributed to data collection. The authors would like to thank Ronnie Aronson for his input and guidance during the development of this manuscript. All authors had full access to all of the data in this study and take complete responsibility for the integrity of the data and accuracy of the data analysis.

Disclosures. Bo Ahrén has received honoraria for lecturing and/or consultancy from AstraZeneca, Boehringer Ingelheim, GlaxoSmithKline, Merck, Novartis, Novo Nordisk, Sanofi, and Takeda. Gagik Galstyan has received fees from AstraZeneca, Boehringer Ingelheim, Merck Sharp \& Dohme, Novo Nordisk, and Sanofi. Jean-Francois Gautier has received fees from AstraZeneca, Eli Lilly, Novartis, Novo Nordisk, and Sanofi. Francesco Giorgino has received fees from AstraZeneca, Boehringer Ingelheim, Bristol-Myers Squibb, Eli Lilly, Janssen, Lifescan Animas, Merck Sharp \& Dohme, Novartis, Novo Nordisk, Roche Diagnostics, Sanofi, and Takeda. Fernando Gomez-Peralta has received fees for advisory panels from AstraZeneca, Novo Nordisk, and Sanofi, for speaker bureaus from AstraZeneca, Boehringer Ingelheim, Bristol-Myers Squibb, Eli Lilly, Novo Nordisk, and Sanofi, and has received research support from Boehringer Ingelheim, Eli Lilly, Novo Nordisk, and Sanofi. Michael Krebs has received research support from Sanofi and speaker and consulting fees from AstraZeneca, Novartis, Novo Nordisk, and Sanofi. Elena Nikonova is an employee of
Artech Information Systems, LLC, under contract with Sanofi as a Clinical Data Associate. William Stager is an employee of Sanofi. Hernando Vargas-Uricoechea has received fees for advisory panels and speaker bureaus from Sanofi.

Compliance with Ethics Guidelines. The analysis in this article is based on previously conducted studies and does not involve any new studies of human or animal subjects performed by any of the authors.

Open Access. This article is distributed under the terms of the Creative Commons Attribution-NonCommercial 4.0 International License (http://creativecommons.org/licenses/ by-nc/4.0/), which permits any noncommercial use, distribution, and reproduction in any medium, provided you give appropriate credit to the original author(s) and the source, provide a link to the Creative Commons license, and indicate if changes were made.

\section{REFERENCES}

1. Kahn SE, Cooper ME, Del PS. Pathophysiology and treatment of type 2 diabetes: perspectives on the past, present, and future. Lancet. 2014;383: 1068-83.

2. Ahren B. Glucagon: early breakthroughs and recent discoveries. Peptides. 2015;67:74-81.

3. Sandoval DA, D'Alessio DA. Physiology of proglucagon peptides: role of glucagon and GLP-1 in health and disease. Physiol Rev. 2015;95:513-48.

4. Meier JJ. GLP-1 receptor agonists for individualized treatment of type 2 diabetes mellitus. Nat Rev Endocrinol. 2012;8:728-42.

5. American Diabetes Association. Diagnosis and classification of diabetes mellitus. Diabetes Care. 2013;36:S67-74.

6. Garber AJ, Abrahamson MJ, Barzilay JI, et al. American Association of Clinical Endocrinologists' 
comprehensive diabetes management algorithm 2013 consensus statement-executive summary. Endocr Pract. 2013;19:536-57.

7. Petersen $A B$, Knop FK, Christensen M. Lixisenatide for the treatment of type 2 diabetes. Drugs Today (Barc). 2013;49:537-53.

8. Werner U, Haschke G, Herling AW, Kramer W. Pharmacological profile of lixisenatide: a new GLP-1 receptor agonist for the treatment of type 2 diabetes. Regul Pept. 2010;164:58-64.

9. Ahrén B, Gautier JF, Berria R, Stager W, Aronson R, Bailey CJ. Pronounced reduction of postprandial glucagon by lixisenatide: a meta-analysis of randomized clinical trials. Diabetes Obes Metab. 2014;16:861-8.

10. Ahrén B, Leguizamo DA, Miossec P, Saubadu S, Aronson R. Efficacy and safety of lixisenatide once-daily morning or evening injections in type 2 diabetes inadequately controlled on metformin (GetGoal-M). Diabetes Care. 2013;36: 2543-50.

11. Rosenstock J, Hanefeld M, Shamanna P, et al. Beneficial effects of once-daily lixisenatide on overall and post-prandial glycemic levels without significant excess of hypoglycemia in type 2 diabetes inadequately controlled on a sulfonylurea with or without metformin (GetGoal-S). J Diabetes Complications. 2014;28:386-92.

12. Lorenz M, Pfeiffer C, Steinstrasser A, et al. Effects of lixisenatide once daily on gastric emptying in type 2 diabetes-relationship to postprandial glycemia. Regul Pept. 2013;185:C1-8.

13. Meier JJ, Rosenstock J, Hincelin-Mery A, et al. Contrasting effects of lixisenatide and liraglutide on postprandial glycemic control, gastric emptying, and safety parameters in patients with type 2 diabetes on optimized insulin glargine with or without metformin: a randomized, open-label trial. Diabetes Care. 2015;38:1263-73.

14. Unger RH, Cherrington AD. Glucagonocentric restructuring of diabetes: a pathophysiologic and therapeutic makeover. J Clin Invest. 2012;122:4-12.

15. Kramer CK, Zinman B, Choi H, Connelly PW, Retnakaran R. The impact of chronic liraglutide therapy on glucagon secretion in type 2 diabetes: insight from the LIBRA trial. J Clin Endocrinol Metab. 2015;100:3702-9.

16. Kolterman OG, Buse JB, Fineman MS, et al. Synthetic exendin-4 (exenatide) significantly reduces postprandial and fasting plasma glucose in subjects with type 2 diabetes. J Clin Endocrinol Metab. 2003;88:3082-9. 